\title{
Near-infrared light reduces $\beta$-amyloid-stimulated microglial toxicity and enhances survival of neurons: Mechanisms of light therapy for Alzheimer's disease
}

\author{
Yurii V. Stepanov \\ Shenzhen University \\ luliia Golovynska \\ Shenzhen University \\ Renlong Zhang \\ Shenzhen University \\ Sergii Golovynskyi \\ Shenzhen University \\ Liudmyla I. Stepanova \\ Taras Shevchenko National University of Kyiv \\ Oleksandr Gorbach \\ National Cancer Institute of Ukraine \\ Taisa Dovbynchuk \\ Taras Shevchenko National University of Kyiv \\ Liudmyla V. Garmanchuk \\ Taras Shevchenko National University of Kyiv \\ Tymish Y. Ohulchanskyy \\ Shenzhen University \\ Junle Qu ( $\nabla$ jlqu@szu.edu.cn ) \\ Shenzhen University
}

\section{Research Article}

Keywords: Alzheimer's disease, photobiomodulation, microglial metabolism, mitochondrial activity, mitochondrial membrane potential.

Posted Date: March 2nd, 2022

DOI: https://doi.org/10.21203/rs.3.rs-1377965/v1 
License: (c) (i) This work is licensed under a Creative Commons Attribution 4.0 International License. Read Full License 


\section{Abstract \\ Background.}

Low-intensity light can decelerate neurodegenerative disease progression and reduce amyloid $\beta$ (AB) levels in the cortex, though, the cellular and molecular mechanisms by which photobiomodulation protects against neurodegeneration are still in the early stages. Microglia cells play a key role in the pathology of Alzheimer's disease by causing chronic inflammation. We present new results concerning the photobiomodulation of both oxidative stress and microglia metabolism associated with the activation of metabolic processes by $808 \mathrm{~nm}$ near-infrared light.

\section{Methods.}

The studies were carried out using healthy male mice to obtain the microglial cell suspension from the hippocampus. Oligomeric $\beta$-amyloid (1-42) was prepared and used to treat microglia cells. Light irradiation of cells was performed using diode lasers emitting at $808 \mathrm{~nm}\left(30 \mathrm{~mW} / \mathrm{cm}^{2}\right.$ for $5 \mathrm{~min}$, resulting in the dose of $10 \mathrm{~J} / \mathrm{cm}^{2}$ ). Mitochondrial membrane potential, ROS level studies, cell viability, apoptosis and necrosis assays were performed using epifluorescence microscopy. Phagocytosis, nitric oxide and $\mathrm{H}_{2} \mathrm{O}_{2}$ production, arginase and glucose 6-phosphate dehydrogenase activities were measured using standard assays. Cytokines, glucose, lactate, and ATP were measurements with ELISA. As our data were normally distributed, Student's t-test was used.

\section{Results.}

The light induces a metabolic shift from glycolysis to mitochondrial activity in pro-inflammatory microglia affected by oligomeric $A \beta$. Thereby, the level of anti-inflammatory microglia increases. This process is accompanied by a decrease in pro-inflammatory cytokines and an activation of phagocytosis. Light exposure decreases the A $\beta$-induced activity of glucose-6-phosphate dehydrogenase, an enzyme that regulates the rate of the pentose phosphate pathway, which activates nicotinamide adenine dinucleotide phosphate oxidases to further produce ROS. During co-cultivation of neurons with microglia, light prevents the death of neurons, which is caused by ROS produced by A $\beta$-altered microglia.

\section{Conclusions.}

These original data clarify reasons for how photobiomodulation protects against neurodegeneration and support the use of light for therapeutic research in the treatment of Alzheimer's disease.

\section{Background}


The main morbid hallmarks in Alzheimer's disease (AD) have long been recognized as extracellular amyloid- $\beta(A \beta)$ plaques and intraneuronal hyperphosphorylated tau protein (PHF-Tau), which are the main contributors to the development of pathology. Meanwhile, the role of microglia in AD pathogenesis has been assessed relatively recently [1,2]. Microglia are resident phagocytes of the brain, which remodel neural connections [3] and remove apoptotic/necrotic cells [4] and unfolded proteins such as $A \beta$ or neuromelanin. In case of damage, it helps to prevent brain infection by direct phagocytosis of bacteria and viruses [5], since phagocytosis and antigen presentation are part of the innate immune response of microglia [6-8]. Phagocytosis is considered useful for tissue homeostasis, since it helps to limit the spread of neurotoxic molecules from dying cells $[4,9]$, and is also accompanied by a decrease in the production of pro-inflammatory cytokines [10]. Furthermore, a temporary increase in the pro-inflammatory profile of microglia has been observed within phagocytosis of myelin debris $[3,11]$.

There is growing evidence about the role metabolism plays in driving the microglia phenotype. It was shown in transgenic mice that either together $A \beta$ and tau or separate oligomeric and fibrillar species of $A \beta 1-42$ can impair the oxidative phosphorylation system (OXPHOS) of mitochondria in AD [12-14]. Mitochondrial dysfunction has been noted as a primary marker of brain pathology in AD [15], which results in an increase in reactive oxygen species (ROS) concentration, a decrease in ATP production, and an abnormal mitochondrial dynamic [16-22]. Accelerated production of free radicals and decreased ATP synthesis contribute to magnification in the aggregation of misfolded protein, including aggregates which increase the activity of lytic enzymes $\beta$ - and $\gamma$-secretase APP. These processes may enhance the amyloidogenic processing of APP, promoting A $\beta$ plaque formation, neurodegeneration and dementia [2325].

A hypothesis of the mitochondrial cascade has been proposed [26-29], which emphasizes the role of mitochondrial bioenergy in $A D$. According to this hypothesis, $A \beta$ formation is a concomitant rather than a major cause of $A D$ pathology. This is consistent with the discovery that early mitochondrial dysfunction can lead to cognitive impairment, increased $A \beta$ aggregation and pathogenesis of $A D[23,27,28]$. The important role of mitochondria in metabolism regulation is noted, in particular, in the regulation of glycolysis and OXPHOS [23, 30,31], the activity of which determines the efficiency of phagocytosis, ROS generation and the production of pro- or anti-inflammatory cytokines. In macrophages, mitochondriamediated shifts from glycolysis to OXPHOS are required for anti-inflammatory stimuli to repolarize proinflammatory cells [32]. Probably similar metabolic processes regulate the microglia phenotype. Thus, cellular metabolism and mitochondrial status are inextricably linked to pro-inflammatory stimuli, which significantly suppress mitochondrial function. In contrast, efficient mitochondrial respiration and OXPHOS may be important for the formation of reparative and anti-inflammatory phenotype of microglia. It should be noted that there are practically no therapeutic approaches, which can affect the activity of microglia in vivo and change the pro-inflammatory profile of microglia to an alternative one.

In this regard, the need for novel treatments with new technologies are of high interest. Drug-free and noninvasive low level light therapy (LLLT), or photobiomodulation, is one promising approach allowing to stabilise cellular metabolism, primarily through the activation of the mitochondrial respiratory chain, 
resulting in an increased ATP production, and the stimulation of transcription factors [33-36]. LLLT uses low doses of light from red and near-infrared (NIR) lasers to achieve a therapeutic effect and has been applied for the treatments of various neurodegenerative diseases [37, 38]. It has been shown in animal models that it can facilitate neurogenesis and neuroplasticity [39], preserve motor and cognitive skills [40], and reduce $A \beta$ levels in the visual cortex of mice and mitigated plaque load in aged mice [41]. LLLT can decelerate neurodegenerative disease progression, which is difficult to perform through pharmacological interventions. During in vitro experiments, light can improve brain cell survival, decrease apoptosis and necrosis, facilitate oxidative stress and restore mitochondrial function [40,42]. Despite extensive scientific research in this direction, the cellular and molecular mechanisms by which photobiomodulation protects against neurodegeneration are still in the early stages.

Based on the described above LLLT advantages, we studied the effect of $808 \mathrm{~nm}$ light on mitochondriamediated shifts from glycolysis to OXPHOS caused by the activation of mitochondrial respiratory chain. Also, the functional role of light in the modulation of oxidative stress, the inflammatory response and microglia metabolism are investigated.

\section{Materials And Methods 2.1. Animals}

The animal studies were carried out at Taras Shevchenko National University of Kyiv, Ukraine, using healthy male mice, 3 months old (18-20 g) in strict accordance with the Law of Ukraine of 21.02.2006 № 3447-IV "On Protection of Animals from Cruel Treatment" with the recommendations about the general ethical principles of animal experiments in the "Guide for the Care and Use of Laboratory Animals. Washington DC: National Academy Press, 1996." by the National Institutes of Health and the experimental protocols approved by the Bioethics Committee for Animal Experiments in the Institute of Biology and Medicine at Taras Shevchenko National University of Kyiv, Ukraine. Before carrying out the experiments, the mice were maintained in collective cages under standard controlled conditions on a $12 \mathrm{~h}$ light/dark cycle and fed standard rodent chow and water ad libitum.

\subsection{Microglia cell suspension}

To obtain the microglial cell suspension from the hippocampus [43], after euthanasia of the mice by cervical dislocation, the isolated brain tissue was placed on top of an ice-cold $0.9 \% \mathrm{NaCl}$ solution supplemented with $0.2 \%$ of glucose in Petri dishes. The hippocampus was isolated from the brain and homogenized in a Potter homogenizer in $0.9 \% \mathrm{NaCl}$ solution for $10 \mathrm{~min}$ at room temperature. The obtained homogenate was passed through a $40 \mu \mathrm{m}$ cell filter (BD Biosciences Discovery, USA) to extract cell conglomerates. The homogenate was transferred into a tube and centrifuged at $350 \times \mathrm{g}$ for $10 \mathrm{~min}$ at room temperature. The precipitate was suspended in $1 \mathrm{ml}$ of $70 \%$ isotonic PERKOL solution (GE Healthcare, USA) and transferred to a new tube. $2 \mathrm{ml}$ of $50 \%$ isotonic PERKOL solution was carefully layered on a $70 \%$ PERKOL layer. On the top of the $50 \%$ PERKOL layer, $1 \mathrm{ml}$ of phosphate buffer was carefully added and centrifuged for $40 \mathrm{~min}$ at $1200 \times \mathrm{g}$. After centrifugation, two layers with cells were 
obtained. The upper layer, localized at the interface between the phosphate buffer and the $50 \%$ isotonic PERCOL phase, contains all elements of the central nervous system (CNS), except for microglia. The lower layer at the interface between the 70 and $50 \%$ isotonic PERCOL phases contains only microglia cells, devoid of other macrophages of the CNS. The isolated cells were washed in $10 \mathrm{ml}$ of phosphate buffer by centrifugation for $5 \mathrm{~min}$ at room temperature, and the cells were resuspended in a RPMI-1640 medium for further assessment of functional parameters. Cell viability was determined using trypan blue, which was at least $90 \%$.

Determination of the primary microglia derived from mice was performed by flow cytometry using primary rabbit anti-mouse IBA1 Polyclonal antibodies (Invitrogen, USA) and secondary goat anti-rabbit Alexa Fluor 647 antibodies (Invitrogen, USA) (Method and Fig. S1 see in Supplementary Materials).

\subsection{Light treatment}

Light irradiation was performed using diode lasers emitting at $808 \mathrm{~nm}$. Light power density was adjusted to be $30 \mathrm{~mW} / \mathrm{cm}^{2}$ and the light irradiation time was for $5 \mathrm{~min}$, resulting in the irradiation dose of nearly 10 $\mathrm{J} / \mathrm{cm}^{2}$. These light power density and doses were chosen because NIR light with such parameters was shown to provide positive effects on cells and tissues, while not causing cell phototoxicity [44-52].

Prior to the light treatment, microglia cells were labelled with fluorescent probes for MtMP and ROS. The stained cells in a colorless DMEM medium were then irradiated for $5 \mathrm{~min}$. Concurrently with irradiation, the epifluorescence microscopy images of microglia were captured every minute to measure the change of fluorescence signal.

\subsection{Mitochondrial membrane potential and ROS level studies, using epifluorescence microscopy}

Microglia were transferred into $35 \mathrm{~mm}$ glass-bottom dishes and cultured. After $24 \mathrm{~h}$, the growth medium was removed. Then, microglia were incubated for $1 \mathrm{~h}$ at $37^{\circ} \mathrm{C}$ in DMEM medium containing one of the following fluorescence probes: Image-iT ${ }^{T M}$ TMRM reagent MtMP indicator (orange fluorescent, 548/574 $\mathrm{nm}, 1 \mu \mathrm{g} / \mathrm{ml}$ ), or CM-H2DCFDA general oxidative stress indicator of ROS (green fluorescent, 504/525 nm, $2 \mu \mathrm{g} / \mathrm{ml}$, diluted in $4 \mathrm{mM}$ Pluronic F-127 suspension), or MitoSOX ${ }^{\mathrm{TM}}$ mitochondrial superoxide indicator of ROS (red fluorescent, $548 / 605 \mathrm{~nm}, 2 \mu \mathrm{g} / \mathrm{ml}$ ), or ROS-Glo ${ }^{\text {TM }} \mathrm{H}_{2} \mathrm{O}_{2}$ assay, specific for the direct detection of $\mathrm{H}_{2} \mathrm{O}_{2}$ in the medium (green fluorescent, 504/525 nm). Also, $\mathrm{H}_{2} \mathrm{O}_{2}$ indicator fluorescence in the medium was determined using a fluorimeter (Jenway 6270, UK). After incubation with a probe, the stained microglia were thoroughly washed with colorless DMEM. The colorless DMEM was also used in the lightexposure experiments. Changes in the probe fluorescence signal (caused by the MtMP or ROS level) were detected and imaged using a Nikon Eclipse Ti-U microscope. To determine fluorescence changes, the epifluorescence microscopy images were acquired every $1 \mathrm{~min}$. Control epifluorescence microscopy images were always taken in the absence of light irradiation or in the addition of $A \beta$ (Sigma-Aldrich, USA). 
Negative controls were assessed as follows: unstained microglia were examined for autofluorescence in the green and red emission ranges. Following fluorescence probe loading, the cells were incubated in darkness and imaged, exhibiting a low level of fluorescence which was reasonably stable during the experiments.

\subsection{Cell viability, apoptosis and necrosis assays by epifluorescence microscopy}

Neurons were received from Procell laboratories: primary mouse cortical neurons were isolated from C57BL/ 6 embryonic mice. Neuron cells were transferred into a Boyden chamber and placed on the upper compartment with a pore membrane, with microglia cells placed in the lower compartment (Fig. S2, Supplementary Materials). The cells were allowed to adhere. Then, before connecting the compartments, microglia cells were irradiated by $808 \mathrm{~nm}$ light, or treated with $A \beta$, or treated with both $808 \mathrm{~nm}$ light and $A \beta$. After light exposure, $A \beta$ addition or co-cultivation with microglia, DMEM was removed and the cells were incubated at $37^{\circ} \mathrm{C}$ in the medium containing fluorescent probes: $5 \mu \mathrm{g} / \mathrm{ml}$ Annexin $\mathrm{V}(50 \mathrm{~min}), 1$ $\mu \mathrm{g} / \mathrm{ml}$ Calcein (30 min), and $1 \mu \mathrm{g} / \mathrm{ml}$ Propidium lodide (5 min). After dye loading, the cells were washed thoroughly and filled with DMEM. Fluorescent images were captured using a Nikon Eclipse Ti-U microscope and quantified (i.e., the integral fluorescence intensity over the entire area of every image was calculated using the Nikon microscope software).

\subsection{Hydrogen peroxide production}

$\mathrm{H}_{2} \mathrm{O}_{2}$ was quantified using ROS-Glo $\mathrm{H}_{2} \mathrm{O}_{2}$ assay (Sigma-Aldrich, USA) according to the manufacturer's recommendations. Following the experimental treatment, the luminescence of the cell medium lysates at $37^{\circ} \mathrm{C}$ was determined using a CLARIOstar luminescence microplate reader (BMG Labtech, Germany), in comparison to $\mathrm{H}_{2} \mathrm{O}_{2}$ standard curve $(0.013 \mu \mathrm{M}-10 \mathrm{mM})$ [53].

\subsection{Phagocytosis assay}

Isolated microglia cells were plated on 24-well plates at a density of $5 \times 10^{4} \mathrm{cells} / \mathrm{cm}^{2}$ and divided into 4 groups ( 1 - control, 2-808 nm light, 3 - $A \beta$ in darkness, $4-A \beta+808 \mathrm{~nm}$ ), then incubated for $24 \mathrm{~h}$ in a standard incubation medium. Further, after replacing the DMEM medium to a DMEM medium without FBS, microglia were cultivated in the presence (stimulated) or absence (non-stimulated) of $1 \mu \mathrm{M}$ oligomeric $A \beta$ (Sigma-Aldrich, USA) and/or light influence. After a time determined by the experiment, fluorescently labelled $A \beta$ (ThermoFisher Scientific, China) was added to the incubation medium for 30 min. This labelled $A \beta$ was used as a phagocytosis object. To stop phagocytosis, the cells were fixed with $0.4 \%$ formalin. Then, the cells were washed and the fluorescence of non-engulfed $A \beta$ was quenched by addition of $0.2 \%$ trypan blue (ThermoFisher Scientific, UK) for $1 \mathrm{~min}$, while the cellular fluorescence was determined using a fluorimeter (Jenway 6270, UK). The index of cellular fluorescence intensity was determined, it showed the amount of $A \beta$ engulfed by the cells (phagocytosis index) and the number of phagocytic cells per 100 cells in the field of view (index of the phagocytosis coefficient). The counting was carried out based on the readings of at least 3 fields in each dish. 


\subsection{Nitric oxide production, arginase and glucose 6- phosphate dehydrogenase activities}

The level of NO production was measured in the microglia supernatant, using the Griess reaction [54]. The arginase activity in cell lysates was assessed by the method proposed by Classen et al. [55]. G6PD activity was assessed using a commercial assay (Cell Signalling Technology, UK) according to the manufacturer's instructions. All these methods are described in Supplementary Materials.

\subsection{Oligomeric $\beta$-amyloid (1-42) preparation}

The oligomeric $A \beta$ ( $p 1-42$, used at a concentration of $1 \mu \mathrm{M}$ ) synthetic peptide (Sigma-Aldrich, USA) was suspended in 100\% 1,1,1,3,3,3 hexafluoro-2-propanol (HFIP) at $6 \mathrm{mg} / \mathrm{ml}$ and incubated for complete solubilisation under shaking at $37^{\circ} \mathrm{C}$ for $1.5 \mathrm{~h}$, as described previously [56]. To obtain oligomeric $A \beta, H F I P$ was removed by evaporation in a SpeedVac and $A \beta$ was resuspended at a concentration of $5 \mathrm{mM}$ in DMSO and sonicated for $20 \mathrm{~s}$, as described elsewhere [57]. The pre-treated $A \beta$ was diluted in phosphate buffered saline $\left(20 \mathrm{mM} \mathrm{NaH}_{2} \mathrm{PO}_{4}, 140 \mathrm{mM} \mathrm{NaCl}, \mathrm{pH} 7.4\right)$ to $400 \mu \mathrm{M}$. The obtained solution was supplemented by $2 \%$ sodium dodecyl sulphate (SDS; in $\mathrm{H}_{2} \mathrm{O}$ ) to a final concentration of $0.2 \%$ SDS and incubated for $6 \mathrm{~h}$ at $37^{\circ} \mathrm{C}$. Further, the obtained solution was diluted three times with $\mathrm{H}_{2} \mathrm{O}$ and incubated for $18 \mathrm{~h}$ at $37^{\circ} \mathrm{C}$ [13]. This was followed by centrifugation for $20 \mathrm{~min}$ at 3,000×g and concentrating the supernatant to $1.8 \mathrm{ml}$ by dialysis against $5 \mathrm{mM} \mathrm{NaPi}, 35 \mathrm{mM} \mathrm{NaCl} \mathrm{pH} 7.4$ overnight at $6^{\circ} \mathrm{C}$ with a $30-\mathrm{kD}$ centriprep and subsequent centrifugation of the concentrate for $10 \mathrm{~min}$ at $10,000 \times \mathrm{g}$. The obtained supernatant was stored in $100 \mu \mathrm{l}$ aliquots at $-80^{\circ} \mathrm{C}$.

\subsection{A $\beta$ oligomerisation}

HFIP-treated $A \beta$ stored at $-80^{\circ} \mathrm{C}$ in DMSO was oligomerised by dilution and vortexing in PBS followed by incubation overnight at $4^{\circ} \mathrm{C}$ [58]. Oligomer formation was confirmed by Western blot using polyclonal Anti-Amyloid Oligomer antibody (Sigma-Aldrich, USA). Oligomeric A $\beta$ migrated at approximately $38 \mathrm{kDa}$, indicating the presence of hexamers/octamers (Fig. S3, see in Supplementary Materials), which coincides with the literature data [56].

\subsection{Cytokines, glucose, lactate, and ATP measurements with ELISA}

Tumour necrosis factor alpha (TNF-a), interleukin 1 beta (IL1- $\beta$ ), glucose, lactate and ATP was assayed by mouse-specific commercially available kits ELISA, according to the manufacturer's protocols (ThermoFisher Scientific, USA). Bacterial lipopolysaccharide (LPS) (Sigma-Aldrich, USA) was used as a positive control. A multilink spectrophotometer $\mu$ Quant (Bio-Tek, USA) was used to measure optical absorption, that were extrapolated to the calibration curve. Glucose consumption was calculated according to the formula $\mathrm{C} 1-\mathrm{C} 2=\mathrm{C} 3$, where $\mathrm{C} 1$ is the initial glucose concentration in the medium, $\mathrm{C} 2$ is 
the glucose concentration in the medium after incubation with $A \beta$, and $C 3$ is the amount of glucose consumed.

\subsection{Statistical analysis}

Control and sample measurements were subjected to statistical analysis. As our data were normally distributed, Student's $t$-test was used. The difference between two means was considered to be statistically significant, when $p$ was less than 0.05 . The results are expressed as the mean \pm SD.

\section{Results}

\subsection{Light-induced suppression of IL1- $\beta$ and TNF- $\alpha$ interleukin secretion in $A \beta$-treated microglia cells}

In the present study, we aimed to determine the potential of light as a tool for controlling microglial inflammation caused by toxic oligomeric $A \beta$ [59]. The $A \beta$ concentration in $1 \mu \mathrm{M}$ was used, which caused both an increase of pro-inflammatory cytokine secretion and ROS generation, in contrast to nanomolar concentrations, which do not cause an inflammatory response in vitro [60].

The selected concentration of $A \beta(1 \mu \mathrm{M})$ and light irradiation did not cause changes of the isolated microglia viability during the $24 \mathrm{~h}$ period (Fig. $4 \mathrm{~A}$ ). At the same time, $A \beta$ stimulated a pronounced increase in pro-inflammatory cytokines IL1- $\beta$ and TNF- $\alpha$ in the first hours of incubation (blue line on Fig. 4B). After $3 \mathrm{~h}$ the concentration of IL1- $\beta$ increased by $400 \%$, in comparison to the control and remained at the same level during the entire experiment. The concentration of TNF-a smoothly increased and exceeded the control values by $550 \%$ after $6 \mathrm{~h}$, with a subsequent increase during $24 \mathrm{~h}$. Light irradiation, which was applied immediately after adding $A \beta$ to the medium, significantly reduced the production of pro-inflammatory cytokines over the next $24 \mathrm{~h}$ (green line on Fig. 4B).

Further, the light effect on pro-inflammatory cytokine secretion by microglia stimulated with $A \beta$ was clarified. After $6 \mathrm{~h}$ of cell incubation with $A \beta$, the medium was changed (blue and green dotted lines on Fig. 4B) and light irradiation was applied (green dotted line on Fig. 4B). After $12 \mathrm{~h}$, the concentration of IL1- $\beta$ and TNF- $\alpha$ in the medium with non-irradiated microglia exceeded the control values by $250 \%$ and $500 \%$, respectively. After light irradiation, the concentration of IL1- $\beta$ and TNF-a remained at the control values. A relatively small increase in the TNF-a concentration in irradiated microglia was observed by 24 h (Fig. 4B). Thus, $808 \mathrm{~nm}$ light applied after $6 \mathrm{~h}$ of Aß-treated microglia reduced pro-inflammatory cytokine secretion almost to the control values.

\subsection{Light-activated phagocytosis of Aß-treated microglia cells}


One of the hallmarks for an alternative activation of phagocytes is an enhancement of phagocytic activity [61, 62]. Phagocytosis of isolated microglia during $24 \mathrm{~h}$ was assessed by the uptake of fluorescent $A \beta$ added to the incubation medium for 30 min at each time point of measurements (Fig. 2; full-combine photos with a bright field and merged images can be found in Fig. S4, Supplementary Materials). Isolated microglia during planting were divided into 4 groups (1 - control, 2-808 nm light, 3 $A \beta$ in darkness, $4-A \beta+808 \mathrm{~nm}$ ) and incubated for $24 \mathrm{~h}$ in a standard incubation medium. Then, the medium was changed to a serum-free DMEM and the cells of groups 3 and 4 were preincubated with nonfluorescent $A \beta$ for 30 min, $2 h, 4 h, 16 h$, and $24 \mathrm{~h}$ before the addition of fluorescent $A \beta$, which was then added to all groups for 30 min as a marker of phagocytosis. The cells of groups 2 and 4 were irradiated 30 min before the addition of fluorescent $A \beta$ at each time point of measurements. The percentage of phagocytic cells in the first group was taken as the control, since in this group the microglia were not preactivated with $A \beta$ or irradiated.

Microglia preincubated with $A \beta 30$ min before the addition of fluorescent $A \beta$ (group 3), showed the maximum phagocytic response, which exceeded the control values by $29.7 \%$. After $24 \mathrm{~h}$, microglial phagocytosis in this group was $24.8 \%$ lower than in the control. In the first hours after light irradiation, phagocytosis was increased in average by $10 \%$, after $16 \mathrm{~h}$ by $38 \%$, and after $24 \mathrm{~h}$ by $44 \%$ (group 4 ). Light did not affect phagocytosis of non-activated microglia (group 2), which indicates that light specifically promotes cell phagocytosis.

\subsection{Light effect on NO, arginase and G6PD production in A $\beta$-treated microglia cells}

Besides the expression of cytokines and phagocytosis activity, the direction of arginine metabolism is known as a generally accepted indicator of functional polarization of phagocytes. An increase in nitric oxide (NO) production as a result of iNOS activity is taken as a sign of classical activation (the marker for M1 polarization); an increase in arginase activity is considered as a sign of an alternative activation of phagocytes (the marker for M2 polarization). The treatment of isolated microglia with either bacterial LPS, as a positive control, or A $\beta$ causes pro-inflammatory metabolic activation with an increase in NO synthesis (by 82 and $49 \%$ ) with a simultaneous decrease in arginase activity (by 47 and $36 \%$ ), respectively (Fig. 3). Light irradiation, which was applied $6 \mathrm{~h}$ after cell cultivation with LPS and A $\beta$, caused a decrease in NO synthesis and an increase in arginase activity almost to the control values after $12 \mathrm{~h}$.

Among glycolytic enzymes, glucose 6-phosphate dehydrogenase (G6PD) plays an important role since it regulates the activity of the pentose phosphate pathway (PPP), in which there is regeneration of cytosolic nicotinamide adenine dinucleotide phosphate [NADP $(H)$ ] from NADP, which is required for the activation of NADPH oxidase (NOX). NOX is a membrane-bound enzyme complex facing extracellular space; therefore, it is one of the main sources of extracellular ROS, which can be toxic to surrounding cells, including neurons. Balanced G6PD levels are essential for normal cell function, while increased or decreased levels cause cellular damage due to oxidative stress [63]. 
The incubation of microglia with LPS or Ab for $12 \mathrm{~h}$ stimulated G6PD activity by $26 \%$ and $18 \%$, respectively. This coincides with the literature data that confirms G6PD activation in the brains of AD patients, including the hippocampus, para-hippocampal gyrus, parolfactory gyrus, and cerebellum [64].

Light excitation ( $6 \mathrm{~h}$ after $A \beta$ adding) reduced G6PD activity, contributing to a more balanced level corresponding to inactivated microglia (Fig. 3). The light effect on G6PD activity in Ab-treated microglia cells is probably not a direct effect, but a consequence of a change in the overall bioenergetic balance of microglia.

\subsection{Light alters energetic metabolism in A $\beta$-activated microglia cells}

In microglia, the initiation of the classic pro-inflammatory response depends on reprogramming towards glycolytic metabolism [65]. The main markers of glycolytic reprogramming are increased glucose consumption, increased lactate production as a result of decreased mitochondrial respiration, and activation of glycolytic pathway enzymes for the rapid production of ATP providing chemotaxis and phagocytosis [66-70].

The registration of glucose consumption, lactate production, and ATP synthesis of isolated microglia was performed during a $24 \mathrm{~h}$ period (Fig. 4). Glucose consumption was compared between the control, LPS, $A \beta$ activated cells and after light exposure. In each case, glucose was measured in the culture medium at a time from 0 to $24 \mathrm{~h}$, and the difference between the starting and ending glucose concentration referred to the corresponding time point. $6 \mathrm{~h}$ after activation of microglia, glucose consumption increased by $134 \%$ and $83 \%$ in the case of treatment by LPS and $A \beta$, and after 24 h by $93 \%$ and $69 \%$, respectively. Light exposure on microglia incubated with $A \beta$ caused a noticeable decrease in glucose consumption, which in the first hours exceeded the control values by less than $50 \%$, and after $24 \mathrm{~h}$ by $23 \%$.

Initial glucose consumption levels by microglia were similar to lactate released rates (Table. 1). After LPS or $A \beta$ influenced microglia showed a high initial rate of released lactate by $350 \%$ and $275 \%$ higher than in the control after $6 \mathrm{~h}$ and by 350 and $300 \%$ after $24 \mathrm{~h}$, respectively. ATP production decreased during the first hours of cell cultivation with LPS and A $\beta$, reaching a plateau between 6 and 12 h. Light application slowed down lactate formation (after $6 \mathrm{~h}$ ) in relation to the A $\beta$-treated cells, which coincided with the formation rate in the control. After $24 \mathrm{~h}$, lactate production in this group of cells remained by as much as $50 \%$ lower than in the cells without light irradiation. After light irradiation, ATP synthesis approached the control values, and, after $24 \mathrm{~h}$, it exceeded ATP production by $155 \%$ in relation to the Ab-treated cells.

These obtained results have demonstrated the effective influence of light on energetic metabolism of microglia. LPS and Aß-treated microglia showed a high initial rate of glucose consumption and lactate production with a simultaneous decrease in ATP synthesis, that is consistent with literature data [71]. Light reduced glucose consumption and lactate production, stimulating ATP synthesis. This apparently suggests an increase in mitochondrial respiration and a decrease in glycolysis. 
Microglia are known to generate energy for their functions, both through glycolysis and through oxidative phosphorylation of mitochondria. During the inflammatory process, cellular metabolism is reprogrammed from OXPHOS to aerobic glycolysis (Warburg effect). Despite the fact that glycolysis is less efficient in terms of ATP production than mitochondrial respiration, the rate of glucose metabolism during glycolysis is 10-100 times faster than that of OXPHOS. The activation of glycolysis allows microglia to carry out energy-intensive processes such as proliferation, migration, cytokine secretion, and phagocytosis [71]. Quantification of glycolytic and mitochondrial ATP can be determined based on the principle of the Pasteur effect [72]. Decreased mitochondrial function stimulates glycolysis to maintain constant ATP

synthesis, at the same time, pyruvate is reduced to lactate to regenerate oxidized pyridine nucleotides and support glycolysis. In the cells lacking mitochondrial function, glycolysis is the sole process, by which such cells can produce two ATP molecules and two lactate molecules from one cleaved glucose molecule [72]. According to the Pasteur effect, an additional production of lactate resulting from inhibition of respiration is equivalent to a lack of mitochondrial ATP. In our experiments, lactate production by microglia in the control increased by $223 \%$ upon inhibition of mitochondrial respiration with antimycin $A$ (AA). The difference in lactate production in the presence and absence of AA ( $\Delta$-lactate) is ATP produced anaerobically to compensate for the decrease in oxidative phosphorylation following AA inhibition of mitochondrial respiration. Basal lactate production represents glycolytic ATP synthesis [72].

The ratio of $\Delta$-lactate (the difference between glycolytic lactate, that is, basal lactate, and lactate after respiratory inhibition by AA) upon basal lactate, represents the ratio of mitochondrial ATP over glycolytic ATP production. In LPS- or A 3 -treated microglia, basal lactate production increased by $36 \%$ and $23 \%$; at the same time, there was a decrease in the ratio of oxidative-ATP/glycolytic-ATP by $71 \%$ and $52 \%$, respectively. The obtained results demonstrate the dominance of glycolysis over mitochondrial respiration in activated microglia, which corresponds by the literature data [73]. Light irradiation cancelled the effect of $A \beta$-activated mitochondrial respiration and inhibited glycolysis, which is confirmed by a decrease in basal lactate production to the control values and an increase in mitochondrial ATP production by $61 \%$.

\subsection{Light influence on mitochondrial membrane potential}

Mitochondria are recognized as one of the main light acceptors [74]. To understand the mechanism of light action on bioenergetic parameters in microglia and the associated decrease in secretion of proinflammatory cytokines, ROS generation, NO production and activation of phagocytosis, we studied mitochondrial membrane potential (MtMP) under light irradiation. Figure 5 shows the effect of $808 \mathrm{~nm}$ light on the MtMP level in microglia. Representative images show the transmission, epifluorescence and their merged images of the cells labelled with TMRM, a fluorescent probe for MtMP. The changes of the MtMP level (assessed as the integrated TMRM fluorescence signal from the imaged cells) under and after irradiation with NIR light is presented in Fig. 5; the representative epifluorescence microscopy images of the TMRM labelled cells under and after light irradiation are shown in Figure S2, Supplementary Materials. During the first 5 min, the effect of $A \beta$ on MtMP did not differ from the control values (Fig. 5; the epifluorescence microscopy images can be found in Fig. S5A, Supplementary 
Materials). After treating microglia $4 \mathrm{~h}$ with $\mathrm{A} \beta$, MtMP decreased by $10 \%$, and, after 16 and $24 \mathrm{~h}$, by 40 and 56\% compared to the control (Fig. 5, the epifluorescence microscopy images in Fig. S5B, Supplementary Materials). Light, independently alone or with $A \beta$, increased MtMP from the 30th second and reached the maximum value at the 3 rd minute. After 5 min of irradiation and turning off the light, MtMP gradually returned to the control values and reached $38 \%$ after $24 \mathrm{~h}$. MtMP of microglia treated with $A \beta$ and after light exposure showed a great difference in comparison to that treated with $A \beta$ alone. Thus, we can make conclusions after observations that light has a significant effect during the entire time range of measurements (Fig. 5).

\subsection{NIR light abolishes ROS production by A $\beta$-stimulated microglia}

Extracellular ROS generation by means of NOX2 enzyme in microglia is a key response to inflammatory stimuli serving as an antimicrobial defence mechanism [75]. There is also evidence of the activation of this enzyme in $A D$ [76]. The regulator of this enzyme activity is G6PD, the activation of which, in our experiments, increased in A $\beta$-treated microglia; therefore, we investigated the level of extracellular ROS in our model (Fig. 6 and the epifluorescence microscopy images are presented in Fig. S6, Supplementary Materials).

NOX2 is not the only potential cellular source of ROS, as the production of mitochondrial ROS also plays a significant role in many physiological and pathological processes [77]. The investigation of A -treated microglia revealed no changes in general ROS (Fig. 6 and Fig. S6A-B), mitochondrial ROS (Fig. 6 and Fig. S6c-d) as well as ROS in the medium (Fig. 6 and Fig. S6E-F) within 2 h. After 24 h, mitochondrial ROS increased by no more than $10 \%$. Light exposure, both independently and in the presence of $A \beta$ in the first $2 \mathrm{~h}$, stimulated the general (15\%) and mitochondrial (10\%) ROS generation, which by $24 \mathrm{~h}$, in the absence of $A \beta$, decreased almost to the control values. Microglia treated with $A \beta$ for more than $2 \mathrm{~h}$ started to increase ROS in the medium, and, after $24 \mathrm{~h}$, increase ROS on average by $60 \%$, but after light exposure this index did not exceed 15\% (Fig. 6 and the epifluorescence microscopy images are presented in Fig. S6, Supplementary Materials).

ROS generation by immune cells targets pathogens. However, during the AD development, when pathogens are absent, ROS generation can damage brain neurons, contributing to neurodegeneration. A model of in vitro co-cultivation of isolated microglia cells and neurons was used to investigate the relationship between $A \beta$-induced ROS production in microglia and neuronal survival. Experiments, using epifluorescence microscopy images with Calcein (green) to visualize the live cells, Annexin (blue) for apoptosis and Propidium lodide (red) for necrosis detection, showed that $1 \mu \mathrm{M}$ of $A \beta$ has not direct neuronal toxicity within $48 \mathrm{~h}$ (Fig. 7 and the epifluorescence microscopy images are presented in Fig. S7, see in Supplementary Materials). Light exposure and co-cultivation with microglia also have not affected neuronal survival. The $A \beta$ addition into co-cultures significantly reduced the survival rate of neurons, increasing their apoptosis and necrosis. Such an effect was largely prevented by light irradiation of 
microglia, $2 \mathrm{~h}$ after starting of incubation with $A \beta$. The same results have been obtained, using routine counting of the cells stained with trypan blue dye (Fig. S8, Supplementary Materials).

These results suggest that a decrease in neuronal survival during co-culturing with $A \beta$-treated microglia is associated with an increase in ROS generation by microglia. Light irradiation of A $\beta$-treated microglia decreases ROS generation, promoting neuronal survival.

\section{Discussion}

Reactive microglia are recognized as one of the main pathological signs of $A D$. Investigating the metabolism of microglia, we found that the impact of $A \beta$ induces an inflammatory reaction, associated with the metabolic transition from OXPHOS to glycolysis, which coincides with the literature data [6670]. A change in adaptive metabolic reprogramming of microglia supports immune function, which depends on rapid ATP generation for energy-intensive chemotaxis, cytokine production, and phagocytosis [78-80]. The activation of glycolysis and the associated pentose phosphate shunt (PPP) pathway, in which activity is regulated by G6PD, is important for ROS generation through the activation of NOX. ROS are necessary for the degradation of absorbed biomaterials in phagolysosomes [81, 82] and play an important role in the clearance of $A \beta$ and tau. In the brains of $A D$ mice, the proteomic analysis demonstrated a relationship between pro-inflammatory microglia and glycolytic metabolism [83], suggesting a protective function of hyperglycolytic microglia in AD. Oppositely, glycolysis in microglia, which is observed in the aging human brain, is associated with impaired phagocytosis and increased secretion of pro-inflammatory cytokines $[84,85]$. Similar observations were made in cultured microglia and isolated from the brains of AD mice, where microglial glycolysis disrupted chemotaxis and phagocytosis of microglia [86]. Additionally, a number of studies have shown that stimulation of mitochondrial OXPHOS, but not glycolysis, activates microglial phagocytosis of $A \beta[87,88]$. A possible explanation for this contradiction may be associated with the acute and chronic effect of $A \beta$ on microglia function. Since glycolysis is metabolically ineffective [88], a constant dependence on glycolysis in microglia can lead to a disruption of its immune response over time, which we observed in the example of the decrease in phagocytosis. The initial effect of $A \beta$ on microglia activates glycolytic metabolism and stimulates phagocytosis. A chronic $A \beta$ influence causes metabolic dysregulation and a decrease of basic immune functions, including phagocytosis and cytokine secretion [71].

In our experiments, the light effect on glycolytic microglia stimulated by $A \beta$ promoted the restoration of mitochondrial function. The increase in mitochondrial activity reduced the glycolytic metabolism of microglia, which led to the decrease in the secretion of pro-inflammatory cytokines and extracellular ROS generation, enhancing the survival of neurons incubated together with $A \beta$-activated microglia. Another positive factor was a noticeable increase in phagocytosis after light exposure, which decreased with prolonged incubation of microglia with $A \beta$. Similar results, associated with an increase in phagocytosis and a decrease in the production of pro-inflammatory cytokines, after incubation with $A \beta$, were obtained using antibodies that increased the quality of mitochondria by activating mitophagy [89]. Also, the effects of ligands on the translocator protein (TSPO), which is mainly expressed on the outer mitochondrial 
membrane of microglia $[90,91]$, was reported to lead to improved mitochondrial OXPHOR and decreased cell death, being a result of reduced ROS and Aß levels in H1299 cells [92, 93]. However, the use of pharmaceutical drugs required invasive intervention, in contrast to light irradiation.

Based on the obtained data, it can be concluded that after the interaction of $A \beta$ with microglia, it binds to Toll-like receptor 2 or 4 (TLR2 / 4) and activates the pro-inflammatory response [94, 95]. To implement the immune response in microglia, the energy metabolism switches from OXPHOR to glycolysis. The main markers of mitochondrial dysfunction are a decrease in membrane potential and ATP production. On the other hand, glycolysis is activated, the signs of which are an increase in glucose consumption, lactate and glycolytic ATP production, an activation of the rate of glycolysis-limiting enzymes such as G6PD, an increase of ROS production, a decrease in arginase activity, and an increase in iNOS activity. Our results show that the metabolic phenotype changes in A $\beta$-treated microglia, which is associated not only with the transition to glycolysis, but also with the activation of PPP and extracellular DOC production. This is known to indicate the activation of NOX $[96,97]$. Metabolic changes in AD [96] are accompanied by a proinflammatory phenotype [98], but the relationship between these changes and pathology of the disease is unclear. We consider that an increase in extracellular ROS may be crucial for triggering neuroinflammation, since we observed a decrease in neuronal survival when incubated with $A \beta$-treated microglia in our experiments.

The effect of light irradiation $(808 \mathrm{~nm})$ on $A \beta$-treated microglia was reflected in the ability to reverse the action of $A \beta$ on microglial metabolism, affecting mitochondria and, as a consequence, the PPP/NOX, and decreasing ROS generation (Fig. 8). These findings complement the growing evidence that NIR light does not only suppress the production of pro-inflammatory cytokines, but also helps in the regulation of major metabolic changes occurring in activated immune cells $[50,74]$. ROS generation is probably not the single damaging effect of $A \beta$ on the brain, as evidenced by the weak effect of antioxidants in clinical trials in $A D$ [74]. It should be noted that antioxidants are probably affecting inflammation by decreasing surrounding ROS, while NIR alters microglial metabolism, decreasing ROS generation.

NO, a product of iNOS activity, inhibits mitochondrial respiration of pro-inflammatory macrophages [32]. Probably, with a chronic Ab influence, this dysfunction prevents the transformation of microglia into the anti-inflammatory phenotype, leaving it in a metabolically disadvantageous state, which leads to a violation of its immune function. Thus, the inhibition of NO production can improve mitochondrial metabolic abnormalities and promote reprogramming of macrophages towards the anti-inflammatory phenotype. Redirecting microglia from the deleterious phenotype to the regenerative one is a key concept for the development of new therapies targeting these cells [99].

Using light at $808 \mathrm{~nm}$ wavelength, we found the reprogramming of microglia to be associated with mitochondria activation (the increased membrane potential of mitochondria and mitochondrial ATP production) and decreased glycolysis. Today cytochrome c oxidase (CCO), the IV complex of mitochondrial respiratory chain, is recognized as one of the main chromophores that absorb NIR light, since it contains two different copper centers, $\mathrm{CuA}$ and $\mathrm{CuB}$, and two heme centers, heme-a and heme-a3 
[100-104]. NO, an increase in the production of which was recorded after incubation with $A \beta$, can inhibit $\mathrm{CCO}$ by binding to the binuclear center $\mathrm{CuB} / \mathrm{a} 3$ of $\mathrm{CCO}[105,106]$. This inhibition can be explained by direct rivalry between $\mathrm{NO}$ and $\mathrm{O}_{2}$ for the binuclear center, and this binding is reversible. One of the hypotheses suggesting why light can activate mitochondria after their NO blockade is explained by the ability of light to photodissociate non-covalently bound NO, absorbing photon of red/NIR light by CCO, increasing the respiration rate and ATP production [107]. The light ability to reverse the inhibition caused by NO binding to CCO has been shown both in isolated mitochondria and in whole cells [108]. Thus, photodissociation of $\mathrm{NO}$ can be a trigger mechanism for the reprogramming of microglia from glycolysis to OXPHOS after its chronic activation by $A \beta$. This proposed mechanism is illustrated in Fig. 8 .

\section{Limitations}

The main limitation in this study is that in vitro experiments are difficult to interpret and transfer to the whole organism (in vivo), which we intend to do in the future. In this case, the parameters of light delivery to the brain cells through the skin and skull will change accordingly. At this stage, the conclusions are applicable only to in vitro experiments. Therefore, the findings presented in this study should be considered investigatory and will need to be further verified in studies using microglia of different origins and in vivo experiments.

\section{Conclusions}

Ab-treated microglia showed the metabolic changes and shifting to the inflammatory phenotype as well as that $A b$ is a powerful activator of microglial ROS generation by means of NOX. Light exposure can reverse such $A \beta$-induced changes and protect neurons from damage. The regulation of activated microglia, using NIR light, may provide a therapeutic strategy for controlling the progression of neuroinflammatory conditions in Alzheimer's disease. Summarizing, this study provides new insights into the role of NIR light in modulating oxidative stress and microglia metabolism. Because NIR LLLT gives an opportunity to suppress ROS generation and to restore metabolic homeostasis, further investigation of this method has significant potential for therapeutic development.

\section{Abbreviations}

\section{AA}

antimycin $\mathrm{A}$

$A \beta$

Amyloid $\beta$

$A \beta-M$

$A \beta$-treated microglia

$A D$

Alzheimer's disease

Arg 
Arginase

CCO

Cytochrome C Oxidase

CNS

central nervous system

GLUT

glucose transport

G6PD

glucose-6-phosphate dehydrogenase

HFIP

1,1,1,3,3,3 hexafluoro-2-propanol

IL $1-\beta$

interleukin 1 beta

iNOS

Inducible nitric oxide synthase

$\mathrm{I}-\mathrm{V}$

complexes $\mathrm{Cl}-\mathrm{CV}$ of electron transport chain

LLLT

low level light therapy

$\mathrm{M}$

microglia

NADPH/NADP+

Nicotinamide adenine dinucleotide phosphate

NED

$\mathrm{N}$-1-naphthylethylenediamine dihydrochloride

NIR

near-infrared

NO

Nitric oxide

NOX

NADPH Oxidase

OXPHOS

oxidative phosphorylation

PHF-Tau

intraneuronal hyperphosphorylated tau protein

PPP

pentose phosphate pathway

ROS

reactive oxygen species

SDS 
sodium dodecyl sulphate

$\mathrm{SrC}$

Src-family protein kinases

TCA

tricarboxylic acid

TLR

Toll-like receptor

TNF-a

Tumour necrosis factor alpha

TSPO

translocator protein.

\section{Declarations}

\section{Ethics approval and consent to participate}

All procedures were approved by our local animal ethics committee in IBM-KNU Ukraine and in detailed described in the section Materials and Methods.

\section{Consent for publication}

Not applicable

\section{Availability of data and materials}

The datasets used and/or analyzed during the current study are available from the corresponding author on reasonable request.

\section{Competing interests}

None of the authors has a conflict of interest.

\section{Funding}

This work was supported in part by the National Natural Science Foundation of China (61950410610, 61875135, 61525503, 61620106016, 61835009), (Key) Project of Department of Education of Guangdong Province (2016KCXTD007) and Shenzhen Basic Research Project (JCYJ20170818090620324); Ministry of Education and Science of Ukraine (0118U000244).

\section{Authors' contributions}

Conceptualization and design: YVS and IG. Experiments: YVS, IG, RZ, LIS, and TD. Data analysis: YVS, IG, and SG. Figures: IG and SG. Validation of results: YVS, IG, and LIS. Writing of first draft: YVS and IG. 
Editing manuscript: SG, JQ. Material support, supervision and administration: JQ, LVG, and TYO. All authors have edited and approved the submitted version.

\section{Acknowledgments}

Not applicable

\section{References}

1. M.T. Heneka, M.J. Carson, J.E. Khoury, G.E. Landreth, F. Brosseron, D.L. Feinstein, A.H. Jacobs, T. Wyss-Coray, J. Vitorica, R.M. Ransohoff, K. Herrup, S.A. Frautschy, B. Finsen, G.C. Brown, A. Verkhratsky, K. Yamanaka, J. Koistinaho, E. Latz, A. Halle, G.C. Petzold, T. Town, D. Morgan, M.L. Shinohara, V.H. Perry, C. Holmes, N.G. Bazan, D.J. Brooks, S. Hunot, B. Joseph, N. Deigendesch, O. Garaschuk, E. Boddeke, C.A. Dinarello, J.C. Breitner, G.M. Cole, D.T. Golenbock, M.P. Kummer, Neuroinflammation in Alzheimer's disease, Lancet Neurol. 14(4) (2015) 388-405.

2. R.M. Ransohoff, J.E. Khoury, Microglia in Health and Disease, Cold Spring Harbor Perspectives in Biology 8(1) (2016) a020560.

3. R.C. Paolicelli, G. Bolasco, F. Pagani, L. Maggi, M. Scianni, P. Panzanelli, M. Giustetto, T.A. Ferreira, E. Guiducci, L. Dumas, D. Ragozzino, C.T. Gross, Synaptic pruning by microglia is necessary for normal brain development, Science 333(6048) (2011) 1456-1458.

4. D.R. Green, T.H. Oguin, J. Martinez, The clearance of dying cells: table for two, Cell Death Differ. 23(6) (2016) 915-926.

5. R. Nau, S. Ribes, M. Djukic, H. Eiffert, Strategies to increase the activity of microglia as efficient protectors of the brain against infections, Front. Cell. Neurosci. 8 (2014) 138.

6. G.W. Litman, J.P. Cannon, J.P. Rast, New Insights into Alternative Mechanisms of Immune Receptor Diversification, Adv. Immunol. 87 (2005) 209-236.

7. A. Sierra, J.M. Encinas, J.J.P. Deudero, J.H. Chancey, G. Enikolopov, L.S. Overstreet-Wadiche, S.E. Tsirka, M. Maletic-Savatic, Microglia shape adult hippocampal neurogenesis through apoptosiscoupled phagocytosis, Cell Stem Cell 7(4) (2010) 483-495.

8. A. Sierra, O. Abiega, A. Shahraz, H. Neumann, Janus-faced microglia: beneficial and detrimental consequences of microglial phagocytosis, Front. Cell. Neurosci. 7 (2013) 6.

9. S.A. Wolf, H.W.G.M. Boddeke, H. Kettenmann, Microglia in physiology and disease, Annu. Rev. Physiol. 79(1) (2017) 619-643.

10. K. Takahashi, C.D.P. Rochford, H. Neumann, Clearance of apoptotic neurons without inflammation by microglial triggering receptor expressed on myeloid cells-2, J. Exp. Med. 201(4) (2005) 647-657.

11. T.A. Siddiqui, S. Lively, L.C. Schlichter, Complex molecular and functional outcomes of single versus sequential cytokine stimulation of rat microglia, J. Neuroinflammation 13(1) (2016) 66.

12. V. Rhein, X. Song, A. Wiesner, L.M. Ittner, G. Baysang, F. Meier, L. Ozmen, H. Bluethmann, S. Drose, U. Brandt, E. Savaskan, C. Czech, J. Gotz, A. Eckert, Amyloid- and tau synergistically impair the oxidative 
phosphorylation system in triple transgenic Alzheimer's disease mice, Proc. Natl. Acad. Sci. USA 106(47) (2009) 20057-20062.

13. A. Eckert, S. Hauptmann, I. Scherping, J. Meinhardt, V. Rhein, S. Dröse, U. Brandt, M. Fändrich, W.E. Müller, J. Götz, Oligomeric and fibrillar species of $\beta$-amyloid (Aß42) both impair mitochondrial function in P301L tau transgenic mice, J. Mol. Med. 86(11) (2008) 1255-1267.

14. J.W. Lustbader, $A B A D$ directly links $A \beta$ to mitochondrial toxicity in Alzheimer's disease, Science 304(5669) (2004) 448-452.

15. S. Hauptmann, I. Scherping, S. Dröse, U. Brandt, K.L. Schulz, M. Jendrach, K. Leuner, A. Eckert, W.E. Müller, Mitochondrial dysfunction: An early event in Alzheimer pathology accumulates with age in $A D$ transgenic mice, Neurobiol. Aging 30(10) (2009) 1574-1586.

16. X. Zhu, A.K. Raina, H.-g. Lee, G. Casadesus, M.A. Smith, G. Perry, Oxidative stress signalling in Alzheimer's disease, Brain Res. 1000(1-2) (2004) 32-39.

17. X. Wang, B. Su, S.L. Siedlak, P.I. Moreira, H. Fujioka, Y. Wang, G. Casadesus, X. Zhu, Amyloidoverproduction causes abnormal mitochondrial dynamics via differential modulation of mitochondrial fission/fusion proteins, Proc. Natl. Acad. Sci. USA 105(49) (2008) 19318-19323.

18. P.I. Moreira, M.S. Santos, C.R. Oliveira, Alzheimer's disease: A lesson from mitochondrial dysfunction, Antioxid. Redox Sign. 9(10) (2007) 1621-1630.

19. G. Perry, P. Moreira, M. Santos, C. Oliveira, J. Shenk, A. Nunomura, M. Smith, X. Zhu, Alzheimer disease and the role of free radicals in the pathogenesis of the disease, CNS Neurol. Disord. Drug Targets 7(1) (2008) 3-10.

20. W.E. Müller, A. Eckert, C. Kurz, G.P. Eckert, K. Leuner, Mitochondrial dysfunction: Common final pathway in brain aging and Alzheimer's disease - Therapeutic aspects, Mol. Neurobiol. 41(2-3) (2010) 159-171.

21. K. Leuner, S. Hauptmann, R. Abdel-Kader, I. Scherping, U. Keil, J.B. Strosznajder, A. Eckert, W.E. Müller, Mitochondrial dysfunction: The first domino in brain aging and Alzheimer's disease?, Antioxid. Redox Sign. 9(10) (2007) 1659-1676.

22. A. Eckert, K.L. Schulz, V. Rhein, J. Götz, Convergence of amyloid- $\beta$ and tau pathologies on mitochondria in vivo, Mol. Neurobiol. 41(2-3) (2010) 107-114.

23. C. Sharma, S. Kim, Y. Nam, U.J. Jung, S.R. Kim, Mitochondrial dysfunction as a driver of cognitive impairment in Alzheimer's disease, Int. J. Mol. Sci. 22(9) (2021) 4850.

24. B.A.I. Payne, P.F. Chinnery, Mitochondrial dysfunction in aging: Much progress but many unresolved questions, BBA-Bioenergetics 1847(11) (2015) 1347-1353.

25. R. Macdonald, K. Barnes, C. Hastings, H. Mortiboys, Mitochondrial abnormalities in Parkinson's disease and Alzheimer's disease: can mitochondria be targeted therapeutically?, Biochem. Soc. Trans. 46(4) (2018) 891-909.

26. R.H. Swerdlow, S.M. Khan, A "mitochondrial cascade hypothesis" for sporadic Alzheimer's disease, Med. Hypotheses 63(1) (2004) 8-20. 
27. M. Mancuso, V. Calsolaro, D. Orsucci, C. Carlesi, A. Choub, S. Piazza, G. Siciliano, Mitochondria, cognitive impairment, and Alzheimer's disease, Int. J. Alzheimers Dis. 2009 (2009) 1-8.

28. R.H. Swerdlow, J.M. Burns, S.M. Khan, The Alzheimer's disease mitochondrial cascade hypothesis: Progress and perspectives, BBA-Mol. Basis Dis. 1842(8) (2014) 1219-1231.

29. R.H. Swerdlow, G. Perry, J. Avila, M. Tabaton, X. Zhu, Mitochondria and mitochondrial cascades in Alzheimer's disease, J. Alzheimers Dis. 62(3) (2018) 1403-1416.

30. J. Park, H. Choi, J.-S. Min, S.-J. Park, J.-H. Kim, H.-J. Park, B. Kim, J.-I. Chae, M. Yim, D.-S. Lee, Mitochondrial dynamics modulate the expression of pro-inflammatory mediators in microglial cells, J. Neurochem. 127(2) (2013) 221-232.

31. N.A. Devanney, A.N. Stewart, J.C. Gensel, Microglia and macrophage metabolism in CNS injury and disease: The role of immunometabolism in neurodegeneration and neurotrauma, Exp. Neurol. 329 (2020) 113310.

32. J. Van den Bossche, J. Baardman, Natasja A. Otto, S. van der Velden, Annette E. Neele, Susan M. van den Berg, R. Luque-Martin, H.-J. Chen, Marieke C.S. Boshuizen, M. Ahmed, Marten A. Hoeksema, Alex F. de Vos, Menno P.J. de Winther, Mitochondrial dysfunction prevents repolarization of inflammatory macrophages, Cell Rep. 17(3) (2016) 684-696.

33. N.H.C. Souza, R.A.M. Ferrari, D.F.T. Silva, F.D. Nunes, S.K. Bussadori, K.P.S. Fernandes, Effect of lowlevel laser therapy on the modulation of the mitochondrial activity of macrophages, Braz. J. Phys. Ther. 18(4) (2014) 308-314.

34. H. Chung, T. Dai, S.K. Sharma, Y.-Y. Huang, J.D. Carroll, M.R. Hamblin, The nuts and bolts of low-level laser (light) therapy, Ann. Biomed. Eng. 40(2) (2011) 516-533.

35. X. Gao, D. Xing, Molecular mechanisms of cell proliferation induced by low power laser irradiation, J. Biomed. Sci. 16(1) (2009) 4.

36. M.R. Hamblin, M.R. Hamblin, R.W. Waynant, T.N. Demidova, J. Anders, Mechanisms of low level light therapy, Proc. of SPIE, Mechanisms for Low-Light Therapy 6140 (2006) 614001.

37. J.J. Anders, P.R. Arany, G.D. Baxter, R.J. Lanzafame, Light-emitting diode therapy and low-level light therapy are photobiomodulation therapy, Photobiomodulation, Photomedicine, and Laser Surgery 37(2) (2019) 63-65.

38. J. Chang, Y. Ren, R. Wang, C. Li, Y. Wang, X. Ping Chu, Transcranial low-level laser therapy for depression and Alzheimer's disease, Neuropsychiatry 08(02) (2018) 477-483.

39. K.C.N. Duarte, T.T. Soares, A.M.P. Magri, L.A. Garcia, L. Le Sueur-Maluf, A.C.M. Renno, G. Monteiro de Castro, Low-level laser therapy modulates demyelination in mice, J. Photoch. Photobio. B 189 (2018) 55-65.

40. M. Bathini, C.R. Raghushaker, K.K. Mahato, The molecular mechanisms of action of photobiomodulation against neurodegenerative diseases: a systematic review, Cell. Mol. Neurobiol. (2020) 1-17, DOI:10.1007/s10571-020-01016-9.

41. H.F. laccarino, A.C. Singer, A.J. Martorell, A. Rudenko, F. Gao, T.Z. Gillingham, H. Mathys, J. Seo, O. Kritskiy, F. Abdurrob, C. Adaikkan, R.G. Canter, R. Rueda, E.N. Brown, E.S. Boyden, L.-H. Tsai, Gamma 
frequency entrainment attenuates amyloid load and modifies microglia, Nature 540(7632) (2016) 230-235.

42. T. Zhou, T.Y. Ohulchanskyy, J. Qu, Effect of NIR light on the permeability of the blood-brain barriers in in vitro models, Biomed. Opt. Express 12(12) (2021) 7544.

43. M.G. Frank, J.L. Wieseler-Frank, L.R. Watkins, S.F. Maier, Rapid isolation of highly enriched and quiescent microglia from adult rat hippocampus: Immunophenotypic and functional characteristics, J. Neurosci. Methods 151(2) (2006) 121-130.

44. Y.-H. Rhee, J.-H. Moon, S.-H. Choi, J.-C. Ahn, Low-level laser therapy promoted aggressive proliferation and angiogenesis through decreasing of transforming growth factor- $\beta 1$ and increasing of Akt/hypoxia inducible factor-1a in anaplastic thyroid cancer, Photomed. Laser Surg. 34(6) (2016) 229-235.

45. A. Ehrlicher, T. Betz, B. Stuhrmann, D. Koch, V. Milner, M.G. Raizen, J. Kas, Guiding neuronal growth with light, Proc. Natl. Acad. Sci. USA 99(25) (2002) 16024-16028.

46. C.F. Rizzi, J.L. Mauriz, D.S. Freitas Corrêa, A.J. Moreira, C.G. Zettler, L.I. Filippin, N.P. Marroni, J. González-Gallego, Effects of low-level laser therapy (LLLT) on the nuclear factor (NF)-kB signaling pathway in traumatized muscle, Laser. Surg. Med. 38(7) (2006) 704-713.

47. N.A.A. Imrigha, N. Bidin, P.S. Lau, N. Musa, N. Zakaria, G. Krishnan, Photobiomodulation therapy on wound treatment subsequent to Q-switched Nd: YAG laser tattoo removal in rat model, J. Biophotonics 10(10) (2017) 1287-1291.

48. M.R. Hamblin, Mechanisms and applications of the anti-inflammatory effects of photobiomodulation, AIMS Biophysics 4(3) (2017) 337-361.

49. M.V. Pires de Sousa, C. Ferraresi, M. Kawakubo, B. Kaippert, E.M. Yoshimura, M.R. Hamblin, Transcranial low-level laser therapy $(810 \mathrm{~nm})$ temporarily inhibits peripheral nociception: photoneuromodulation of glutamate receptors, prostatic acid phophatase, and adenosine triphosphate, Neurophotonics 3(1) (2016) 015003.

50. J.W. Song, K. Li, Z.W. Liang, C. Dai, X.F. Shen, Y.Z. Gong, S. Wang, X.Y. Hu, Z. Wang, Low-level laser facilitates alternatively activated macrophage/microglia polarization and promotes functional recovery after crush spinal cord injury in rats, Sci. Rep. 7(1) (2017) 1-13.

51. I. Golovynska, S. Golovynskyi, Y.V. Stepanov, L.V. Garmanchuk, L.I. Stepanova, J. Qu, T.Y. Ohulchanskyy, Red and near-infrared light induces intracellular $\mathrm{Ca}^{2+}$ flux via the activation of glutamate N-methyl-D-aspartate receptors, J. Cell. Physiol. 234(9) (2019) 15989-16002.

52. I. Golovynska, S. Golovynskyi, Y.V. Stepanov, L.I. Stepanova, J. Qu, T.Y. Ohulchanskyy, Red and nearinfrared light evokes $\mathrm{Ca}^{2+}$ influx, endoplasmic reticulum release and membrane depolarization in neurons and cancer cells, J. Photochem. Photobiol. B: Biology 214 (2021) 112088.

53. M. Muñoz, M.P. Martínez, M.E. López-Oliva, C. Rodríguez, C. Corbacho, J. Carballido, A. GarcíaSacristán, M. Hernández, L. Rivera, J. Sáenz-Medina, D. Prieto, Hydrogen peroxide derived from NADPH oxidase 4- and 2 contributes to the endothelium-dependent vasodilatation of intrarenal arteries, Redox Biol. 19 (2018) 92-104. 
54. D.J. Joshi, N.M. Chitre, A. Bansal, K.S. Murnane, M.J. D'Souza, Formulation and characterization of microcapsules encapsulating PC12 cells as a prospective treatment approach for Parkinson's disease, AAPS PharmSciTech 22(4) (2021) 149.

55. I.M. Corraliza, M.L. Campo, G. Soler, M. Modolell, Determination of arginase activity in macrophages: a micromethod, J. Immunol. Methods 174(1-2) (1994) 231-235.

56. S. Barghorn, V. Nimmrich, A. Striebinger, C. Krantz, P. Keller, B. Janson, M. Bahr, M. Schmidt, R.S. Bitner, J. Harlan, E. Barlow, U. Ebert, H. Hillen, Globular amyloid beta-peptide1-42 oligomer - a homogenous and stable neuropathological protein in Alzheimer's disease, J. Neurochem. 95(3) (2005) 834-847.

57. A. Ferrari, F. Hoerndli, T. Baechi, R.M. Nitsch, J. Götz, ß-Amyloid induces paired helical filament-like tau filaments in tissue culture, J. Biol. Chem. 278(41) (2003) 40162-40168.

58. W.B. Stine, L. Jungbauer, C. Yu, M.J. LaDu, Preparing synthetic $A \beta$ in different aggregation states, Methods Mol Biol 670 (2010) 13-32.

59. K.N. Dahlgren, A.M. Manelli, W.B. Stine, L.K. Baker, G.A. Krafft, M.J. LaDu, Oligomeric and fibrillar species of amyloid- $\beta$ peptides differentially affect neuronal viability, J. Biol. Chem. 277(35) (2002) 32046-32053.

60. E.S. Wickstead, H.A. Karim, R.E. Manuel, C.S. Biggs, S.J. Getting, S. McArthur, Reversal of $\beta$-amyloidinduced microglial toxicity in vitro by activation of Fpr2/3, Oxid. Med. Cell. Longev. (2020) 2139192.

61. A. Sica, A. Mantovani, Macrophage plasticity and polarization: in vivo veritas, J. Clin. Investig. 122(3) (2012) 787-795.

62. C.A. Butler, A.S. Popescu, E.J.A. Kitchener, D.H. Allendorf, M. Puigdellívol, G.C. Brown, Microglial phagocytosis of neurons in neurodegeneration, and its regulation, J. Neurochem. 158(3) (2021) 621639.

63. M. Tiwari, Glucose 6 phosphatase dehydrogenase (G6PD) and neurodegenerative disorders: Mapping diagnostic and therapeutic opportunities, Genes Dis. 4(4) (2017) 196-203.

64. L. Balazs, M. Leon, Evidence of an oxidative challenge in the Alzheimer's brain, Neurochem. Res. 19(9) (1994) 1131-1137.

65. L.H. Fairley, J.H. Wong, A.M. Barron, Mitochondrial regulation of microglial immunometabolism in Alzheimer's disease, Front. Immunol. 12 (2021) 624538.

66. T.R. Hammond, C. Dufort, L. Dissing-Olesen, S. Giera, A. Young, A. Wysoker, A.J. Walker, F. Gergits, M. Segel, J. Nemesh, S.E. Marsh, A. Saunders, E. Macosko, F. Ginhoux, J. Chen, R.J.M. Franklin, X. Piao, S.A. McCarroll, B. Stevens, Single-cell RNA sequencing of microglia throughout the mouse lifespan and in the injured brain reveals complex cell-state changes, Immunity 50(1) (2019) 253-271.e6.

67. L. Wang, S. Pavlou, X. Du, M. Bhuckory, H. Xu, M. Chen, Glucose transporter 1 critically controls microglial activation through facilitating glycolysis, Mol. Neurodegener. 14(1) (2019) 2.

68. A.J. Freemerman, A.R. Johnson, G.N. Sacks, J.J. Milner, E.L. Kirk, M.A. Troester, A.N. Macintyre, P. Goraksha-Hicks, J.C. Rathmell, L. Makowski, Metabolic reprogramming of macrophages, J. Biol. Chem. 289(11) (2014) 7884-7896. 
69. J. Michl, D.J. Ohlbaum, S.C. Silverstein, 2-Deoxyglucose selectively inhibits Fc and complement receptor-mediated phagocytosis in mouse peritoneal macrophages II. Dissociation of the inhibitory effects of 2-deoxyglucose on phagocytosis and ATP generation, J. Exp. Med. 144(6) (1976) 14841493.

70. S. Pavlou, L. Wang, H. Xu, M. Chen, Higher phagocytic activity of thioglycollate-elicited peritoneal macrophages is related to metabolic status of the cells, J. Inflamm. (Lond) 14(1) (2017) 4.

71. S.H. Baik, S. Kang, W. Lee, H. Choi, S. Chung, J.-I. Kim, I. Mook-Jung, A breakdown in metabolic reprogramming causes microglia dysfunction in Alzheimer's disease, Cell Metabolism 30(3) (2019) 493-507.e6.

72. H. Holmsen, L.M. Robkin, Effects of antimycin $A \beta$ and 2-deoxyglucose on energy metabolism in washed human platelets, Thromb. Haemost. 42(05) (2018) 1460-1472.

73. J. Cheng, R. Zhang, Z. Xu, Y. Ke, R. Sun, H. Yang, X. Zhang, X. Zhen, L.-T. Zheng, Early glycolytic reprogramming controls microglial inflammatory activation, J. Neuroinflammation 18(1) (2021) 129.

74. M. Hamblin, Photobiomodulation for Alzheimer's disease: Has the light dawned?, Photonics 6(3) (2019) 77.

75. R. Spooner, Ö. Yilmaz, The role of reactive-oxygen-species in microbial persistence and inflammation, Int. J. Mol. Sci. 12(1) (2011) 334-352.

76. M.W. Ma, J. Wang, Q. Zhang, R. Wang, K.M. Dhandapani, R.K. Vadlamudi, D.W. Brann, NADPH oxidase in brain injury and neurodegenerative disorders, Mol. Neurodegener. 12(1) (2017) 7.

77. D.B. Zorov, M. Juhaszova, S.J. Sollott, Mitochondrial reactive oxygen species (ROS) and ROSinduced ROS release, Physiol. Rev. 94(3) (2014) 909-950.

78. J. Brusco, K. Haas, Interactions between mitochondria and the transcription factor myocyte enhancer factor 2 (MEF2) regulate neuronal structural and functional plasticity and metaplasticity, J. Physiol. 593(16) (2015) 3471-3481.

79. Abhishek K. Jha, Stanley C.-C. Huang, A. Sergushichev, V. Lampropoulou, Y. Ivanova, E. Loginicheva, K. Chmielewski, Kelly M. Stewart, J. Ashall, B. Everts, Edward J. Pearce, Edward M. Driggers, Maxim N. Artyomov, Network integration of parallel metabolic and transcriptional data reveals metabolic modules that regulate macrophage polarization, Immunity 42(3) (2015) 419-430.

80. K.R. Feingold, J.K. Shigenaga, M.R. Kazemi, C.M. McDonald, S.M. Patzek, A.S. Cross, A. Moser, C. Grunfeld, Mechanisms of triglyceride accumulation in activated macrophages, J. Leukoc. Biol. 92(4) (2012) 829-839.

81. J. Geng, X. Sun, P. Wang, S. Zhang, X. Wang, H. Wu, L. Hong, C. Xie, X. Li, H. Zhao, Q. Liu, M. Jiang, Q. Chen, J. Zhang, Y. Li, S. Song, H.-R. Wang, R. Zhou, R.L. Johnson, K.-Y. Chien, S.-C. Lin, J. Han, J. Avruch, L. Chen, D. Zhou, Kinases Mst1 and Mst2 positively regulate phagocytic induction of reactive oxygen species and bactericidal activity, Nat. Immunol. 16(11) (2015) 1142-1152.

82. S.-j. Koo, B. Szczesny, X. Wan, N. Putluri, N.J. Garg, Pentose phosphate shunt modulates reactive oxygen species and nitric oxide production controlling trypanosoma cruzi in macrophages, Front. Immunol. 9 (2018) 202. 
83. E.C.B. Johnson, E.B. Dammer, D.M. Duong, L. Ping, M. Zhou, L. Yin, L.A. Higginbotham, A. Guajardo, B. White, J.C. Troncoso, M. Thambisetty, T.J. Montine, E.B. Lee, J.Q. Trojanowski, T.G. Beach, E.M. Reiman, V. Haroutunian, M. Wang, E. Schadt, B. Zhang, D.W. Dickson, N. Ertekin-Taner, T.E. Golde, V.A. Petyuk, P.L. De Jager, D.A. Bennett, T.S. Wingo, S. Rangaraju, I. Hajjar, J.M. Shulman, J.J. Lah, A.I. Levey, N.T. Seyfried, Large-scale proteomic analysis of Alzheimer's disease brain and cerebrospinal fluid reveals early changes in energy metabolism associated with microglia and astrocyte activation, Nat. Med. 26(5) (2020) 769-780.

84. V. Mela, B.C. Mota, M. Milner, A. McGinley, K.H.G. Mills, Á.M. Kelly, M.A. Lynch, Exercise-induced reprogramming of age-related metabolic changes in microglia is accompanied by a reduction in senescent cells, Brain Behav. Immun. 87 (2020) 413-428.

85. M. Olah, E. Patrick, A.-C. Villani, J. Xu, C.C. White, K.J. Ryan, P. Piehowski, A. Kapasi, P. Nejad, M. Cimpean, S. Connor, C.J. Yung, M. Frangieh, A. McHenry, W. Elyaman, V. Petyuk, J.A. Schneider, D.A. Bennett, P.L. De Jager, E.M. Bradshaw, A transcriptomic atlas of aged human microglia, Nat. Commun. 9(1) (2018) 539.

86. A. Mclntosh, V. Mela, C. Harty, A.M. Minogue, D.A. Costello, C. Kerskens, M.A. Lynch, Iron accumulation in microglia triggers a cascade of events that leads to altered metabolism and compromised function in APP/PS1 mice, Brain Pathol. 29(5) (2019) 606-621.

87. R.-Y. Pan, J. Ma, X.-X. Kong, X.-F. Wang, S.-S. Li, X.-L. Qi, Y.-H. Yan, J. Cheng, Q. Liu, W. Jin, C.-H. Tan, Z. Yuan, Sodium rutin ameliorates Alzheimer's disease-like pathology by enhancing microglial amyloid- $\beta$ clearance, Sci. Adv. 5(2) (2019) eaau6328.

88. A. Rubio-Araiz, O.M. Finucane, S. Keogh, M.A. Lynch, Anti-TLR2 antibody triggers oxidative phosphorylation in microglia and increases phagocytosis of $\beta$-amyloid, J. Neuroinflammation 15(1) (2018) 247.

89. E.F. Fang, Y. Hou, K. Palikaras, B.A. Adriaanse, J.S. Kerr, B. Yang, S. Lautrup, M.M. Hasan-Olive, D. Caponio, X. Dan, P. Rocktäschel, D.L. Croteau, M. Akbari, N.H. Greig, T. Fladby, H. Nilsen, M.Z. Cader, M.P. Mattson, N. Tavernarakis, V.A. Bohr, Mitophagy inhibits amyloid- $\beta$ and tau pathology and reverses cognitive deficits in models of Alzheimer's disease, Nat. Neurosci. 22(3) (2019) 401-412.

90. M. Cosenza-Nashat, M.L. Zhao, H.S. Suh, J. Morgan, R. Natividad, S. Morgello, S.C. Lee, Expression of the translocator protein of $18 \mathrm{kDa}$ by microglia, macrophages and astrocytes based on immunohistochemical localization in abnormal human brain, Neuropathol. Appl. Neurobiol. 35(3) (2009) 306-328.

91. B. Gulyas, B. Makkai, K. Nagy, A. Vas, P. Kasa, J. Andersson, T. Suhara, K. Suzuki, M. Higuchi, Z. Beliczai, K. Gulya, L. Csiba, C. Halldin, In vitro evidence for competitive TSPO binding of the imaging biomarker candidates vinpocetine and two iodinated DAA1106 analogues in post mortem autoradiography experiments on whole hemisphere human brain slices, Curr. Radiopharm. 2(1) (2009) 42-48.

92. A.M. Barron, L.M. Garcia-Segura, D. Caruso, A. Jayaraman, J.W. Lee, R.C. Melcangi, C.J. Pike, Ligand for translocator protein reverses pathology in a mouse model of Alzheimer's disease, J. Neurosci. 
33(20) (2013) 8891-8897.

93. N. Zeineh, N. Denora, V. Laquintana, M. Franco, A. Weizman, M. Gavish, Efficaciousness of low affinity compared to high affinity TSPO ligands in the inhibition of hypoxic mitochondrial cellular damage induced by cobalt chloride in human lung H1299 cells, Biomedicines 8(5) (2020) 106.

94. C. Hughes, M.L. Choi, J.-H. Yi, S.-C. Kim, A. Drews, P.S. George-Hyslop, C. Bryant, S. Gandhi, K. Cho, D. Klenerman, Beta amyloid aggregates induce sensitised TLR4 signalling causing long-term potentiation deficit and rat neuronal cell death, Commun. Biol. 3(1) (2020) 79.

95. K. Tahara, H.D. Kim, J.J. Jin, J.A. Maxwell, L. Li, K.i. Fukuchi, Role of toll-like receptor signalling in A uptake and clearance, Brain 129(11) (2006) 3006-3019.

96. S. Mostafavi, C. Gaiteri, S.E. Sullivan, C.C. White, S. Tasaki, J. Xu, M. Taga, H.-U. Klein, E. Patrick, V. Komashko, C. McCabe, R. Smith, E.M. Bradshaw, D.E. Root, A. Regev, L. Yu, L.B. Chibnik, J.A. Schneider, T.L. Young-Pearse, D.A. Bennett, P.L. De Jager, A molecular network of the aging human brain provides insights into the pathology and cognitive decline of Alzheimer's disease, Nat. Neurosci. 21(6) (2018) 811-819.

97. C. Nagy, A. Haschemi, Time and demand are two critical dimensions of immunometabolism: The process of macrophage activation and the pentose phosphate pathway, Front. Immunol. 6 (2015) 164.

98. L.A.J. O'Neill, R.J. Kishton, J. Rathmell, A guide to immunometabolism for immunologists, Nat. Rev. Immunol. 16(9) (2016) 553-565.

99. M. Fumagalli, M. Lombardi, P. Gressens, C. Verderio, How to reprogram microglia toward beneficial functions, Glia 66(12) (2018) 2531-2549.

100. S. Passarella, T. Karu, Absorption of monochromatic and narrow band radiation in the visible and near IR by both mitochondrial and non-mitochondrial photoacceptors results in photobiomodulation, J. Photoch. Photobio. B 140 (2014) 344-358.

101. B. Beauvoit, T. Kitai, B. Chance, Contribution of the mitochondrial compartment to the optical properties of the rat liver: a theoretical and practical approach, Biophys. J. 67(6) (1994) 2501-2510.

102. M.G.S.P.D. Pastore, Specific helium-neon laser sensitivity of the purified cytochrome c oxidase, Int. J. Radiat. Biol. 76(6) (2009) 863-870.

103. T.I. Karu, S.F. Kolyakov, Exact action spectra for cellular responses relevant to phototherapy, Photomed. Laser Surg. 23(4) (2005) 355-361.

104. M.T.T. Wong-Riley, H.L. Liang, J.T. Eells, B. Chance, M.M. Henry, E. Buchmann, M. Kane, H.T. Whelan, Photobiomodulation directly benefits primary neurons functionally inactivated by toxins, J. Biol. Chem. 280(6) (2005) 4761-4771.

105. B. Beltran, A. Mathur, M.R. Duchen, J.D. Erusalimsky, S. Moncada, The effect of nitric oxide on cell respiration: A key to understanding its role in cell survival or death, Proc. Natl. Acad. Sci. USA 97(26) (2000) 14602-14607.

106. G.C. Brown, Regulation of mitochondrial respiration by nitric oxide inhibition of cytochrome $c$ oxidase, BBA-Bioenergetics 1504(1) (2001) 46-57. 
107. T.I. Karu, L.V. Pyatibrat, N.I. Afanasyeva, Cellular effects of low power laser therapy can be mediated by nitric oxide, Lasers Surg. Med. 36(4) (2005) 307-314.

108. V. Borutaite, A. Budriunaite, G.C. Brown, Reversal of nitric oxide-, peroxynitrite- and S-nitrosothiolinduced inhibition of mitochondrial respiration or complex I activity by light and thiols, BBABioenergetics 1459(2-3) (2000) 405-412.

\section{Tables}

Table 1 is not available with this version.

\section{Figures}

\section{Figure 1}

Microglia cell viability and secretion of TNF- $\alpha$ and IL1- $\beta(\mathrm{pg} / \mathrm{ml})$ by microglia depending on the incubation time with $A \beta(1 \mu M)$. (A) Cell viability determined using trypan blue solution. (B) TNF- $\alpha$ and IL1- $\beta$ assayed by mouse-specific ELISA kits for measuring optical absorption. The cells were irradiated with lowintensity light at $808 \mathrm{~nm}$ with a light dose of $10 \mathrm{~J} / \mathrm{cm}^{2}$. The data are presented as the mean $\pm \mathrm{SD}(N=8)$; $p<0.05$ indicates the data with a statistically significant difference evaluated in relation to the control level (Student's $t$-test).

\section{Figure 2}

NIR light activation phagocytosis of $A \beta$-treated microglia cells. Changes in the fluorescence signal from $A \beta$ following stimulation by non-fluorescent $A \beta$, low-intensity light at $808 \mathrm{~nm}$ with $10 \mathrm{~J} / \mathrm{cm}^{2}$, and both $A \beta$ and light over time was recorded. The representative transmission microscopy images show phagocytosis of $A \beta$ by microglia after $30 \mathrm{~min}, 2 \mathrm{~h}, 4 \mathrm{~h}, 16 \mathrm{~h}$, and $24 \mathrm{~h}$. The data are presented as the mean $\pm \mathrm{SD}(N=8) ;{ }^{*} p<0.05$ indicates data with a statistically significant difference evaluated in relation to the control level (Student's $t$-test). 


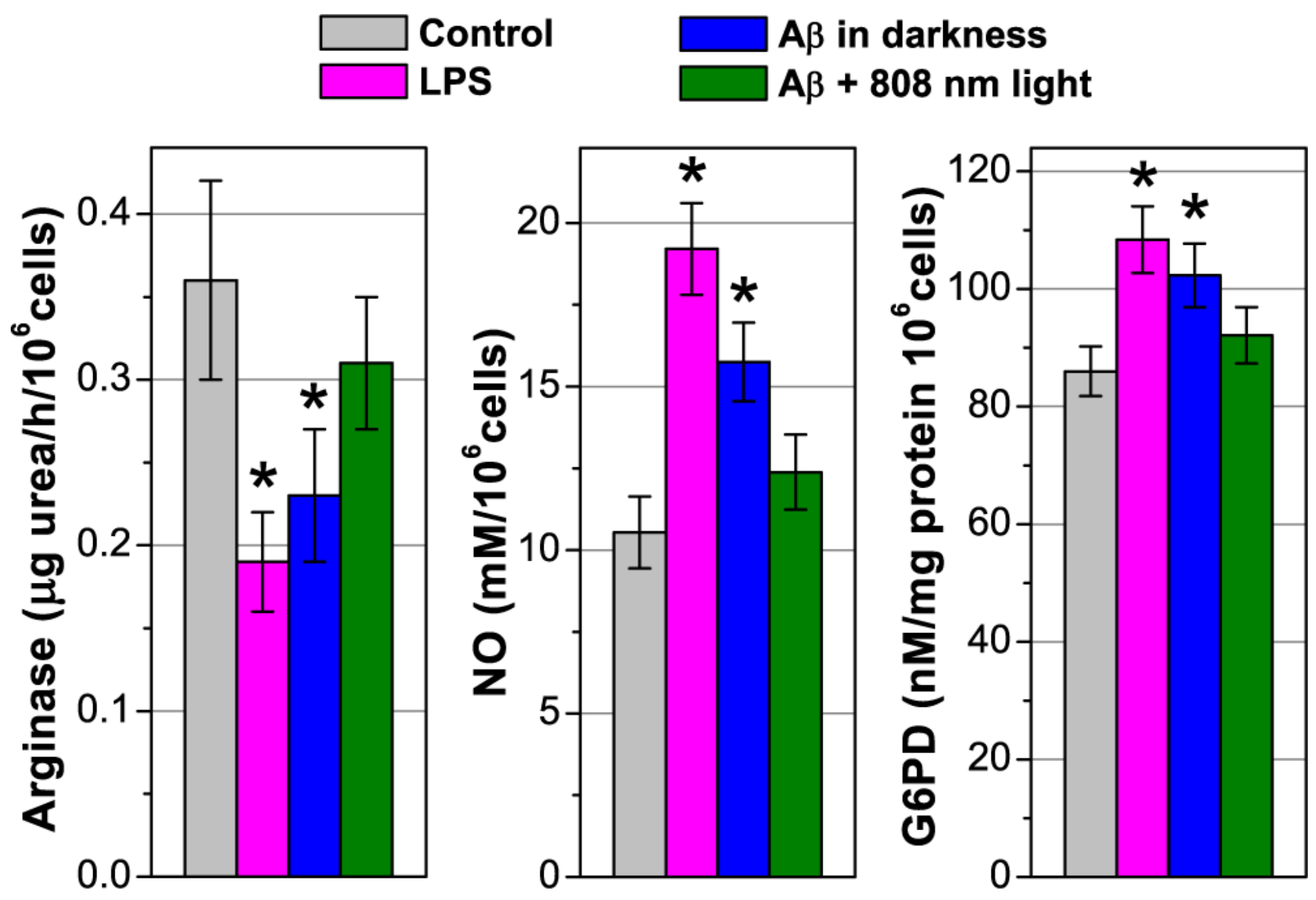

Figure 3

NIR light effect on NO, arginase and G6PD production in Aß-treated microglia cells. The cells were irradiated with low-intensity light at $808 \mathrm{~nm}$ with $10 \mathrm{~J} / \mathrm{cm}^{2}$. The data are presented as the mean $\pm \mathrm{SD}(N=$ 8); $p<0.05$ indicates data with a statistically significant difference evaluated in relation to the control level (Student's $t$-test).

Figure 4

NIR light effect on glucose consumption, lactate production and ATP synthesis in A $\beta$-treated microglia cells. The cells were irradiated with low-intensity light at $808 \mathrm{~nm}$ with $10 \mathrm{~J} / \mathrm{cm}^{2}$. The data are presented as the mean $\pm \mathrm{SD}(N=8) ; p<0.05$ indicates data with a statistically significant difference evaluated in relation to the control level (Student's t-test). 


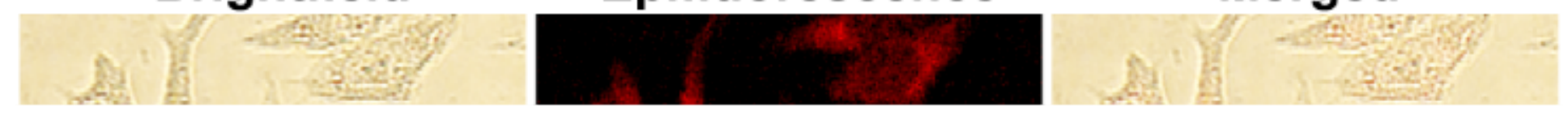

Figure 5

Mitochondrial membrane potential activation following $A \beta$ and $808 \mathrm{~nm}$ light exposure. Microscope images showing the transmission bright field, epifluorescence and merged images of macrophages labelled with TMRM. Changes in the MtMP level (TMRM fluorescence signal) following stimulation by low-intensity light during $5 \mathrm{~min}$ at $30 \mathrm{~mW} / \mathrm{cm}^{2}$ (equivalent to $10 \mathrm{~J} / \mathrm{cm}^{2}$ ). Dynamics of MtMP (the integrated fluorescence signal) following irradiation with red/NIR light. The data are presented as mean \pm $\operatorname{SD}(N=5) ; p<0.05$ indicates data with a statistically significant difference evaluated in relation to the control fluorescence level (Student's $t$-test). 


\section{Figure 6}

\section{Light effect on the general ROS generation, mitochondrial ROS generation and ROS in the medium}

measured for A $\beta$-treated microglia. Microscope images showing the transmission bright field, epifluorescence and merged images of macrophages labelled with CM-H2DCFDA for general ROS detection, MitoSOX ${ }^{\mathrm{TM}}$ for mitochondrial ROS detection and ROS-GIO ${ }^{\mathrm{TM}}$ for ROS in the medium. Graphs show the dynamics of ROS generation following stimulation by low-intensity light at $808 \mathrm{~nm}$ with 10 $\mathrm{J} / \mathrm{cm}^{2}$ during $24 \mathrm{~h}$. The data are presented as the mean $\pm \mathrm{SD}(N=5) ; p<0.05$ indicates data with a statistically significant difference evaluated in relation to the control level (Student's $t$-test).

\section{Figure 7}

Increased neuron cell viability after NIR exposure in a co-culture with $A \beta$ stimulated microglia. (A) Schematic illustration of neuron cell cultivation in the Boyden chamber under different conditions, from left to right: control, light application $\left(808 \mathrm{~nm}, 10 \mathrm{~J} / \mathrm{cm}^{2}\right), A \beta$ addition, co-cultivation with microglia (M), co-cultivation with $A \beta$-treated microglia $(A \beta-M)$, co-cultivation with $A \beta-M$ after light application. (B) Epifluorescence microscopy images showing the effect of $808 \mathrm{~nm}$ light, $A \beta$, co-cultivation with $M, c 0-$ cultivation with $A \beta-M$, co-cultivation with $A \beta-M+808 \mathrm{~nm}$ light on neuron cell viability with Calcein (green) to visualize the live cells, Annexin (blue) for apoptosis and Propidium lodide (red) for necrosis detection during $48 \mathrm{~h}$. (C) Columns present the quantification of viable, apoptotic and necrotic cells. The data are presented as the mean $\pm \mathrm{SD}(N=8)$; ${ }^{*} p<0.05$ indicates data with a statistically significant difference evaluated in relation to the control level, and ${ }^{\#} p<0.05$ indicates data with a statistically significant difference evaluated in relation to the level during co-cultivation with $A \beta$-treated microglia (Student's $t$ test). Scale bare $100 \mu \mathrm{m}$.

\section{Figure 8}

NIR light and $A \beta$ are the metabolic regulators of microglial phenotype and function. The proposed metabolic processes are based on the research in this article and from research papers focused on microglia and referenced in the text. Abbreviations: Arg: Arginase; CCO: Cytochrome C Oxidase; GLUT: glucose transport; G6PD: glucose-6-phosphate dehydrogenase; I-V: complexes $\mathrm{Cl}-\mathrm{CV}$ of electron transport chain; iNOS: Inducible nitric oxide synthase; NADPH/NADP+: Nicotinamide adenine dinucleotide 
phosphate; NO: Nitric oxide; NOX: NADPH Oxidase; OXPHOS: oxidative phosphorylation; PPP: pentose phosphate pathway; ROS: reactive oxygen species; Src: Src-family protein kinases; TCA: tricarboxylic acid; TLR: Toll-like receptor.

\section{Supplementary Files}

This is a list of supplementary files associated with this preprint. Click to download.

- SupplementaryMaterialsStepanov.pdf

- Graphicalabstract.png 